TEIXEIRA, Alessandra Vanessa e GIRELLI, Camile Serraggio, Miriam Fecchio. Direito ambiental comparado: argentina, brasil e o estudo normativo-jurídico de suas águas. Revista Eletrônica Direito e Política, Programa de Pós-Graduação Stricto Sensu em Ciência Jurídica da UNIVALI, Itajaí, v.10, n.3, 2o quadrimestre de 2015. Disponível em: www.univali.br/direitoepolitica - ISSN 1980-7791.

\title{
DIREITO AMBIENTAL COMPARADO: ARGENTINA, BRASIL E O ESTUDO NORMATIVO-JURÍDICO DE SUAS ÁGUAS
}

\author{
ENVIRONMENTAL LAW COMPARED: ARGENTINA, BRAZIL AND THE STUDY \\ REGULATORY-LEGAL OF ITS WATERS
}

\section{Alessandra Vanessa Teixeira ${ }^{1}$ Camile Serraggio Girelli}

SUMÁRIO: Introdução; 1 . Método Comparado; 2 . Método Comparado no Direito Ambiental; 3. Estudo Comparado: Proteção Jurídica Das Águas no Brasil e na Argentina; Considerações Finais; Referências das Fontes Citadas.

\section{RESUMO}

O presente trabalho tem como objetivo realizar um estudo comparado referente à proteção jurídica das águas nos países Argentina e Brasil. Para realizar o estudo foi utilizado o método comparado, restringindo-se à análise dos dispositivos constitucionais de ambos os países, bem como suas respectivas legislações infraconstitucionais. Pode-se perceber que a legislação brasileira, tanto na seara constitucional como na infraconstitucional, está mais avançada do que a legislação argentina. Isto porque a Constituição brasileira, além de ter sido promulgada em data mais recente, traz expressamente previsões de proteção às águas. Além disso, o Brasil conta com legislações específicas, como o Código de Águas e a Lei da Política Nacional de Recursos Hídricos. Enquanto que a Constituição argentina, só os prevê de forma indireta, sendo que não existe uma legislação tão específica como no Brasil. Observa-se que no país vizinho, são as províncias que tem a competência legislativa para tal atribuição.

PALAVRAS-CHAVE: Direito Ambiental; Método Comparado; Direito das Águas; Argentina; Brasil.

\footnotetext{
${ }^{1}$ Mestranda em Direito pela Universidade de Passo Fundo. Bolsista da Capes. Advogada. Graduada em Direito pela Universidade de Passo Fundo. Pós-Graduada em Direito Público pela Faculdade Meridional - IMED.

2 Advogada. Graduada em Direito pela Universidade de Passo Fundo. Aluna erasmus da Universidade de Coimbra. Mediadora Familiar pelo Centro de Estudos da Família e do Indivíduo. Pós-Graduada em Direito Processual Civil pela Universidade Anhanguera-Uniderp. Aluna Especial no Curso de Mestrado na Universidade de Passo Fundo.
} 
TEIXEIRA, Alessandra Vanessa e GIRELLI, Camile Serraggio, Miriam Fecchio. Direito ambiental comparado: argentina, brasil e o estudo normativo-jurídico de suas águas. Revista Eletrônica Direito e Política, Programa de Pós-Graduação Stricto Sensu em Ciência Jurídica da UNIVALI, Itajaí, v.10, n.3, 2o quadrimestre de 2015. Disponível em: www.univali.br/direitoepolitica - ISSN 1980-7791.

\section{ABSTRACT}

This paper aims to conduct a comparative study regarding the legal protection of waters in the countries Argentina and Brazil. For the study we used the comparison method, restricted to the analysis of constitutional provisions of both countries and their respective infra legislation. One can see that Brazilian law, both in constitutional harvest as in infra, is more advanced than the Argentine legislation. This is because the Brazilian constitution, and has been enacted in most recently, expressly provides protection to the waters of forecasts. Moreover, Brazil has specific legislation such as the Water Code and the Law of National Water Resources Policy. While the Argentine Constitution provides only indirectly, and there is no legislation as specific as in Brazil. It is observed that in the neighboring country are the provinces that has the legislative competence to such assignment.

KEY-WORDS: Environmental Law; Compared Method; Waters of Law; Argentina; Brazil.

\section{INTRODUÇÃO}

A importância do método comparado para o Direito Ambiental se fixa na medida em que a legislação que versa sobre Direito Ambiental nacional é fortemente influenciada por legislações internacionais. Isto porque o meio ambiente não pode ser visto de forma fracionada, pois seus problemas são transfronteiriços, tendo, assim, que se fazer um estudo lato sensu, comparando legislações de países vizinhos para buscar uma maior integração de ecossistemas.

A partir disso, pretendeu-se, no presente estudo, fazer uma análise das legislações da Argentina e do Brasil com direcionamento específico em suas águas. Comparando as legislações constitucionais de ambos, bem como as infraconstitucionais, no caso do Brasil as federais, e, no caso da Argentina, as nacionais. 
TEIXEIRA, Alessandra Vanessa e GIRELLI, Camile Serraggio, Miriam Fecchio. Direito ambiental comparado: argentina, brasil e o estudo normativo-jurídico de suas águas. Revista Eletrônica Direito e Política, Programa de Pós-Graduação Stricto Sensu em Ciência Jurídica da UNIVALI, Itajaí, v.10, n.3, 2o quadrimestre de 2015. Disponível em: www.univali.br/direitoepolitica - ISSN 1980-7791.

\section{MÉTODO COMPARADO}

Ao comparar-se elementos do cotidiano, tais como pessoas, ideias, predileções, objetos, animais, entre outros, leva-se em conta cada uma de suas particularidades e isso gera um certo confronto com um elemento oposto. Ao estabelecer essa comparação acaba-se fazendo uma análise das semelhanças e das diferenças para, ao final, exprimir uma valoração, ou seja, conceituar-se como melhor ou pior.

Já no âmbito jurídico, o método de pesquisa comparado permite a análise de legislações, costumes, institutos, sistemas e ordenamentos diferentes, sejam eles entre municípios, estados, nações ou organizações distintas. Assim, é comum encontrar na doutrina, na jurisprudência, nos artigos jurídicos, bem como nos bancos acadêmicos, análises comparativas.

Orides Mezzaroba e Cláudia Monteiro ensinam que "o método comparativo pode ser utilizado tanto para efetuar comparações no presente, no pretérito, ou as duas concomitantemente ${ }^{\prime \prime}$. Isto é, podem-se comparar elementos históricos do direito criados, por exemplo, na Roma antiga com legislações atualmente vigentes, razão pela qual o método comparado é tão utilizado nas pesquisas jurídicas.

Contudo, como menciona Rodolfo Sacco

A comparação pressupõe o conhecimento da regra jurídica estrangeira. Este conhecimento visualizado abstratamente pode suscitar simpatia, ou pode também conduzir a reações polêmicas. De qualquer modo, a comparação não comporta necessariamente uma valoração, positiva ou negativa, favorável ou crítica, das outras instituições.

A comparação é potencialmente imparcial e tem o direito de sê-lo. As ciências que se ocupam do homem não devem, enquanto ciências, interrogar-se para avaliar os comportamentos dos homens - a língua, a religião, a ideologia, o direito -, concedendo-lhes atestados de boa

3 MEZZAROBA, Orides. MONTEIRO, Cláudia Servilha. Manual de Metodologia da Pesquisa no Direito. São Paulo: Saraiva, 2003, p. 91. 
TEIXEIRA, Alessandra Vanessa e GIRELLI, Camile Serraggio, Miriam Fecchio. Direito ambiental comparado: argentina, brasil e o estudo normativo-jurídico de suas águas. Revista Eletrônica Direito e Política, Programa de Pós-Graduação Stricto Sensu em Ciência Jurídica da UNIVALI, Itajaí, v.10, n.3, 2o quadrimestre de 2015. Disponível em: www.univali.br/direitoepolitica - ISSN 1980-7791.

conduta e de conformidade à razão e à lógica. As ciências humanas têm por escopo conhecer os comportamentos dos homens e buscar a seguir qual seria a lógica própria e específica, e não apenas as razões intrínsecas e determinantes de tais comportamentos. Se as ciências humanas não encontram essa lógica e estas razões, é porque faltou uma pesquisa de qualidade. ${ }^{4}$

Assim, diferentemente das comparações feitas com elementos do cotidiano, a pesquisa comparativa não comporta, necessariamente uma valoração seja ela positiva ou negativa do objeto em questão, ela tem o direito de ser imparcial.

Diante disso, nota-se que a pesquisa comparativa não pode ser feita de forma indiscriminada, pois presume o conhecimento da regra jurídica estrangeira, somado a uma análise do contexto jurídico-social-econômico-religiosoepistemológico em que está inserida.

Em outras palavras, a análise comparativa não pode ser feita tão somente pela avaliação da legislação ou do instituto em si, com citações desconexas, mas deve, também, levar em consideração o posicionamento doutrinário que a sustenta ou a critica, bem como deve ser feita uma análise direcionada a um ponto de vista, seja ele político, antropológico, histórico, filosófico, social, econômico, jurídico, entre outros.

Devido a essas inúmeras possibilidades que o método comparado oferece ao pesquisador, muitos juristas tem se posicionado de forma crítica à sua aplicação. Apesar de o direito comparado existir desde Montesquieu ${ }^{5}$ no século XVIII (e

${ }^{4}$ SACCO, Rodolfo. Introdução ao Direito Comparado. Tradução Véra Jacob de Fradera. São Paulo: Editora Revista dos Tribunais, 2001, p. 27-28.

${ }^{5}$ Recusando submeter-se aos princípios religiosos e morais, e distanciando-se do racionalismo abstrato do século XVII, Montesquieu deu início ao estudo descritivo e comparativo dos fatos humanos, formulando um novo conceito de lei, que constituía, então, uma inovação teórica e representava sua principal contribuição para a formação da ciência social. (...) Tendo cada domínio de seres suas próprias leis, elas não podem ser apreendidas senão a partir dos próprios fatos, pela comparação e pesquisa, pelo tateio, e não pela intuição de essências. Montesquieu não pretende extrair princípios de preconceitos, mas da natureza mesma das coisas. MONTESQUIEU, Charles Louis de Secondat. Do Espírito das Leis. Introdução e Notas de Gonzague Truc; Tradução de Fernando Henrique Cardoso e Leôncio Martins Rodrigues. $2^{a}$ ed. Coleção: Os Pensadores. São Paulo: Abril Cultural, 1979, p. XVIII. 
TEIXEIRA, Alessandra Vanessa e GIRELLI, Camile Serraggio, Miriam Fecchio. Direito ambiental comparado: argentina, brasil e o estudo normativo-jurídico de suas águas. Revista Eletrônica Direito e Política, Programa de Pós-Graduação Stricto Sensu em Ciência Jurídica da UNIVALI, Itajaí, v.10, n.3, 2o quadrimestre de 2015. Disponível em: www.univali.br/direitoepolitica - ISSN 1980-7791.

informalmente, as suas raízes serem encontradas em Aristóteles), mesmo os profissionais do direito comparado devem admitir que, talvez, dada à vastidão do seu tema, como uma disciplina acadêmica, o método comparado permanece em estado incipiente de desenvolvimento. ${ }^{6}$

Com a intenção de aperfeiçoar os resultados da pesquisa, o autor Tiago Marrara nos ensina de que há, pelo menos, seis etapas a serem necessariamente observadas para o uso do método comparado, quais sejam:

1) a escolha dos objetos de comparação; 2) a apresentação das características e funções jurídicas de cada objeto nos respectivos ordenamentos jurídicos; 3) a contextualização de cada objeto sob a perspectiva macro-jurídica e, quando possível e necessário, sob a perspectiva extrajurídica; 4) a comparação em sentido estrito; 5) o exame das diferenças e pontos comuns encontrados ao longo da comparação e 6) a elaboração de críticas aos objetos estudados e de eventuais propostas de aperfeiçoamento dos sistemas em que eles se inserem com base nas conclusões comparativas. ${ }^{7}$

Segundo Zweigert e Kötz "o objetivo de alguns juristas comparativistas têm sido alcançar a harmonia, se não a unificação das leis. ${ }^{\prime 8}$ Contudo, essa unificação nos parece um tanto utópica tendo em vista o multiculturalismo global. Para Marc Ancel "é evidente, entretanto, que a comparação, até mesmo por definição, não

\footnotetext{
${ }^{6}$ Tradução livre do texto: "Owing to this range, many legal scholars have taken a critial attitude toward the field. Although "comparative law" has existed since Montesquieu in te eighteenth century (and informally, its roots may be traced as far back as Aristotle), even practitioners of comparative law must concede that, perhaps dua to the vastness of its subject matter, as an academic discipline, it presently remains at an inchoate state of development." GINSBURG, TOM. MONATERI, Pier Giuseppe. PARISI, Francesco. Classiscs in Comparative Law: An Introduction. Disponível em: https://snt146. mail.live.com/mail/ViewOfficePreview.aspx?messageid=mgKp1w4hcE5RGmnAAh Wtezyg2\&folderid $=$ flinbox\&attindex $=0 \& c p=-1 \&$ attdepth $=0 \& n=18404086$. Acesso em: 27 de maio de 2015.

7 MARRARA, Tiago. Método Comparativo e Direito Administrativo. Disponível em: http://www.unigran.br/revista_juridica/ed_atual/artigos/artigo02.pdf. Acesso em 28 de maio de 2015.

8 Tradução livre do texto: "The objective of many comparative lawyers has been to achieve harmonisation if not unification of laws.". ZWEIGERT, See K. KÖTZ, H. An Introduction to Comparative Law, 3rd edn (traslated by Tony Weir, Oxford, Oxford University Press, 1998) 1518, 58-62. In: In: HOECKE, Mark Van (ed.). Methodologies of Legal Research: Which Kind of Method for What Kind of Discipline? Oxford: Hart Publishing, 2011, p.155.
} 
TEIXEIRA, Alessandra Vanessa e GIRELLI, Camile Serraggio, Miriam Fecchio. Direito ambiental comparado: argentina, brasil e o estudo normativo-jurídico de suas águas. Revista Eletrônica Direito e Política, Programa de Pós-Graduação Stricto Sensu em Ciência Jurídica da UNIVALI, Itajaí, v.10, n.3, 2o quadrimestre de 2015. Disponível em: www.univali.br/direitoepolitica - ISSN 1980-7791.

consiste em isolar, mas ao contrário, em aproximar, ou em confrontar os dois termos que constituem o seu objeto. ${ }^{\prime \prime}$

Para outros juristas comparativistas, no entanto, o foco do direito comparado é apresentar uma análise da dinâmica interna e dos princípios legais existente nos países estudados ${ }^{10}$, o objetivo não é buscar uma valoração no sentido de eleger um sistema melhor, superior, mais apropriado que o outro, na verdade o objetivo do método comparado é sistematizar uma análise, extraindo dela os benefícios e avanços apresentados para que os objetos da comparação possam se fortalecer e evoluir da melhor maneira possível.

\section{MÉTODO COMPARADO NO DIREITO AMBIENTAL}

Como visto anteriormente, o método comparado desempenha um papel fundamental para o desenvolvimento da ciência do Direito, proporcionando meios para suprir as falhas e imperfeições nos ordenamentos jurídicos. Nesse sentido,

Constata-se que o método científico para a análise jurídica parte de premissas absolutas, contudo não é possível entender plenamente 0 processo de desenvolvimento jurídico-ambiental desconsiderando os elementos sociais e culturais do direito. Como ponto de partida tem-se as situações jurídicas, político-econômicas e ambientais de diversos países. Os disparates neste âmbito comparativo são praticamente incomensuráveis e por esta razão as criações jurídicas do Primeiro Mundo nem sempre podem ser transpostas a outros ordenamentos; se o podem, isso nem sempre parece ser uma solução viável e pouco problemática. No contexto internacional de modernização de suas leis, o Brasil optou nas últimas décadas por uma 'recepção seletiva'

\footnotetext{
${ }^{9}$ ANCEL, Marc. Utilidade e Métodos do Direito Comparado. Tradução de Sérgio José Porto. Porto Alegre, Fabris, 1980, p. 73.

${ }^{10}$ Tradução livre do texto: "For many comparative lawyers, however, the focus of comparative law is to present an analysis of internal dynamics and principles of the existing laws of the countries studied" BELL, John. Legal Research and the Distinctiveness od Comparative Law. In: HOECKE, Mark Van (ed.). Methodologies of Legal Research: Which Kind of Method for What Kind of Discipline? Oxford: Hart Publishing, 2011, p.155.
} 
TEIXEIRA, Alessandra Vanessa e GIRELLI, Camile Serraggio, Miriam Fecchio. Direito ambiental comparado: argentina, brasil e o estudo normativo-jurídico de suas águas. Revista Eletrônica Direito e Política, Programa de Pós-Graduação Stricto Sensu em Ciência Jurídica da UNIVALI, Itajaí, v.10, n.3, 2o quadrimestre de 2015. Disponível em: www.univali.br/direitoepolitica - ISSN 1980-7791.

do Direito Ambiental estrangeiro e das soluções práticas do mesmo. ${ }^{11}$

Sendo assim, a utilização do método comparado é fundamental para o Direito Ambiental, uma vez que é através do estudo comparativo da proteção e da gestão ambiental entre diferentes nações que é possível encontrar meios para melhorar, ajustar e trazer para cada país opções para que o meio ambiente global possua um melhor amparo jurídico e consiga sobreviver e proporcionar uma sadia qualidade de vida às presentes e futuras gerações.

Segundo Paulo de Bessa Antunes,

Em matéria de Direito Ambiental, a importância do método comparativo se avulta na medida em que o próprio Direito Ambiental interno é fortemente influenciado pelos ordenamentos jurídicos de outros países. Uma das principais razões para que assim seja é o fato de que os problemas ambientais não respeitam fronteiras e que, no entanto, a sua superação somente poderá ocorrer com uma legislação internacional que se baseie em princípios e normas bastante próximos, sob pena de ineficiência e frustração. ${ }^{12}$

$\mathrm{Na}$ verdade, não há como pensar o meio ambiente de forma fracionada, fronteiriça, stricto sensu, pois os ecossistemas são interdependentes, abertos. Sendo assim, não há como fazer um estudo coerente sem considerar o ambiente em sentido lato sensu, e, assim, interagir com a legislação dos países próximos para buscar uma interação mais realista.

Cabe aqui mencionar que renomados juristas ambientais do mundo todo, em duas reuniões realizadas sobre o Direito Ambiental, chegaram a conclusões importantes para o meio ambiente. A primeira foi a Reunião Mundial das Associações de Direito Ambiental, realizada na França no ano de 1990, tendo

\footnotetext{
11 RAMOS, Erasmo Marcos. Direito ambiental comparado: Brasil-Alemanha-EUA: uma análise exemplificada dos instrumentos ambientais brasileiros à luz do direito comparado. Maringá: Midiograf II, 2009, p. 1.
}

12 ANTUNES, Paulo de Bessa. Direito Ambiental. 11 ed., Rio de Janeiro: Lumen Juris, 2008 , p. 263. 
TEIXEIRA, Alessandra Vanessa e GIRELLI, Camile Serraggio, Miriam Fecchio. Direito ambiental comparado: argentina, brasil e o estudo normativo-jurídico de suas águas. Revista Eletrônica Direito e Política, Programa de Pós-Graduação Stricto Sensu em Ciência Jurídica da UNIVALI, Itajaí, v.10, n.3, 2o quadrimestre de 2015. Disponível em: www.univali.br/direitoepolitica - ISSN 1980-7791.

sido originada a denominada Declaração de Limoges. Esta serviu como preparação para a segunda reunião, a Conferência Mundial de 1992, realizada no Brasil, a qual gerou a Declaração denominada Rio-92. Ambas as Declarações indicaram temas para futuras recomendações e uma delas foi referente ao ensino do Direito Ambiental. "O ensino do Direito Ambiental aos juristas e aos não juristas deve dar lugar de destaque ao Direito Internacional e ao Direito Comparado e integra-se na visão global e multidisciplinar do ambiente."13

Relativamente ao método comparado no direito ambiental, quanto aos países integrantes do Mercosul, Paulo Afonso Leme Machado refere

[...] a procura da semelhança de institutos jurídicos está a indicar que as instâncias centrais ou federais de cada País têm um papel insubstituível na unificação das normas gerais ambientais. A omissão desses níveis de poder levaria a uma pulverização das normas, com a possibilidade de conflitos, o que dificultaria a integração pretendida no Mercado Comum do Sul. ${ }^{14}$

Nesse sentido, preleciona Pes

Ademais, o Direito Comparado é, ao mesmo, um meio e uma expressão da cooperação internacional do plano jurídico. Problemas tão atuais e tão universais como os do meio ambiente são abordados por juristas de diferentes países por meio da pesquisa comparativa, resultando, normalmente, em cooperação internacional. ${ }^{15}$

Ainda, segundo o mesmo autor, "a criação e o desenvolvimento dos organismos internacionais, tanto no plano regional como no plano mundial, atuam em favor

\footnotetext{
${ }^{13}$ MUKAI, Toshio. Direito ambiental sistematizado. 4. ed. Rio de Janeiro: Forense Universitária, 2004, p. 146-147.

${ }^{14}$ MACHADO, Paulo Affonso Leme. Direito Ambiental Brasileiro. 22. ed. São Paulo: Malheiros Editores, 2014, p. 146

15 PES, João Hélio Ferreira. O Mercosul e as águas: a harmonização, via Mercosul, das normas de proteção às águas transfronteiriças do Brasil e Argentina. Santa Maria: Ed. da UFSM, 2005, p. 18.
} 
TEIXEIRA, Alessandra Vanessa e GIRELLI, Camile Serraggio, Miriam Fecchio. Direito ambiental comparado: argentina, brasil e o estudo normativo-jurídico de suas águas. Revista Eletrônica Direito e Política, Programa de Pós-Graduação Stricto Sensu em Ciência Jurídica da UNIVALI, Itajaí, v.10, n.3, 2o quadrimestre de 2015. Disponível em: www.univali.br/direitoepolitica - ISSN 1980-7791.

da cooperação jurídica comparativa em matéria ambiental". ${ }^{16}$ Afirma também que "o comparativismo jurídico é de suma importância para uma proteção ambiental efetiva e harmônica no Mercosul."17

Com o exposto acima, fica claro que o método comparado é essencial para o estudo do Direito Ambiental, uma vez que se deve pensar o meio ambiente como um todo, como planeta. E isso quer dizer que não adianta um país ter normas eficazes se o outro não tem, pois se um não cuida, todos os outros saem prejudicados.

\section{ESTUDO COMPARADO: PROTEÇÃO JURÍdICA DAS ÁGUAS NO BRASIL E NA ARGENTINA}

A água é elemento imprescindível para a vida dos seres vivos, é um bem vital que pertence a todos os habitantes do planeta. Diante disso, é de fundamental importância e urgência a sua abordagem face o risco de escassez de água previsto no mundo.

Fatores naturais, aumento populacional, poluição provocada por atividades humanas, consumo excessivo e alto grau de desperdício de água prejudicam ainda mais a disponibilidade desse precioso líquido para uso humano. ${ }^{18}$

Não se trata aqui de fazer um estudo histórico, ou sobre a evolução do direito das águas no Brasil e na Argentina, mas sim de trazer as normas federais do Brasil e as normas nacionais da Argentina, atuais, que tratam da proteção das águas, e fazer um comparativo entre elas, pois

\footnotetext{
16 PES, João Hélio Ferreira. O Mercosul e as águas: a harmonização, via Mercosul, das normas de proteção às águas transfronteiriças do Brasil e Argentina. p. 18.

17 PES, João Hélio Ferreira. O Mercosul e as águas: a harmonização, via Mercosul, das normas de proteção às águas transfronteiriças do Brasil e Argentina. p. 19.

18 MACHADO, Roberto Ferreira. Água um direito fundamental. In: Revista Direito Ambiental e sociedade, Caxias do Sul, v. 1, n. 1, p. 348, jan./jun. 2011.
} 
TEIXEIRA, Alessandra Vanessa e GIRELLI, Camile Serraggio, Miriam Fecchio. Direito ambiental comparado: argentina, brasil e o estudo normativo-jurídico de suas águas. Revista Eletrônica Direito e Política, Programa de Pós-Graduação Stricto Sensu em Ciência Jurídica da UNIVALI, Itajaí, v.10, n.3, 2o quadrimestre de 2015. Disponível em: www.univali.br/direitoepolitica - ISSN 1980-7791.

Os sistemas jurídicos de ambos pertencem ao mesmo sistema (sentido amplo) ou à mesma família de direito, ou seja, o sistema romano-germânico, ou, também denominado civilista, que influenciou consideravelmente os países da América Latina, fazendo com que Brasil e Argentina tenham um sistema jurídico similar. ${ }^{19}$

Seguindo essa linha e dando início ao estudo comparado ora proposto, será analisada primeiramente a proteção jurídica das águas sob a égide constitucional de cada um dos países.

\subsection{As águas nas Constituições}

A Constituição Brasileira de 1988 trouxe grandes avanços nesta seara, a primeira delas é com relação à dominialidade das águas que passaram a ser públicas, dos Estados e da União somente, acabando-se com o regime de águas particulares ou comuns que eram previstas no Código Civil e no Código de Águas. ${ }^{20}$

Então, quanto à dominialidade das águas no âmbito da União, dispõe o art. 20 da CF/88, em seus incisos III, IV, V, VI, VII e VIII:

Art. 20. São bens da União: (...) III - os lagos, rios e quaisquer correntes de água em terrenos de seu domínio, ou que banhem mais de um Estado, sirvam de limites com outros países, ou se estendam a território estrangeiro ou dele provenham, bem como os terrenos marginais e as praias fluviais; IV - as ilhas fluviais e lacustres nas zonas limítrofes com outros países; as praias marítimas; as ilhas oceânicas e as costeiras, excluídas, destas, as que contenham a sede de Municípios, exceto aquelas áreas afetadas ao serviço público e a unidade ambiental federal, e as referidas no art. 26, II; V - os recursos naturais da plataforma continental e da zona econômica exclusiva; VI - o

19 PES, João Hélio Ferreira. O Mercosul e as águas: a harmonização, via Mercosul, das normas de proteção às águas transfronteiriças do Brasil e Argentina. p. 19.

20 PES, João Hélio Ferreira. O Mercosul e as águas: a harmonização, via Mercosul, das normas de proteção às águas transfronteiriças do Brasil e Argentina. p. 41. 
TEIXEIRA, Alessandra Vanessa e GIRELLI, Camile Serraggio, Miriam Fecchio. Direito ambiental comparado: argentina, brasil e o estudo normativo-jurídico de suas águas. Revista Eletrônica Direito e Política, Programa de Pós-Graduação Stricto Sensu em Ciência Jurídica da UNIVALI, Itajaí, v.10, n.3, 2o quadrimestre de 2015. Disponível em: www.univali.br/direitoepolitica - ISSN 1980-7791.

mar territorial; VII - os terrenos de marinha e seus acrescidos; VIII - os potenciais de energia hidráulica. ${ }^{21}$

O artigo 26, I da CF/88 arrola as águas pertencentes ao domínio dos Estados:

Art. 26. Incluem-se entre os bens dos Estados: I - as águas superficiais ou subterrâneas, fluentes, emergentes e em depósito, ressalvadas, neste caso, na forma da lei, as decorrentes de obras da União. ${ }^{22}$

Paulo Afonso Leme Machado refere que "a redação ampla do art. 26, I, da CF/1988 alarga significativamente o domínio dos recursos hídricos estaduais". ${ }^{23}$ Quanto à competência legislativa sobre as águas, a Constituição Federal de 1988 assim dispõe: "Art. 22. Compete privativamente à União legislar sobre: (...) IV - águas, energia, informática, telecomunicações e radiodifusão". Ainda, em seu parágrafo único "Parágrafo único. Lei complementar poderá autorizar os Estados a legislar sobre questões específicas das matérias relacionadas neste artigo". ${ }^{24}$

Agora, quanto à competência material ou executiva sobre as águas, o art. 21 da CF/88 em seus incisos XVIII, XIX e XX prevê:

Art. 21. Compete à União: XVIII - planejar e promover a defesa permanente contra as calamidades públicas, especialmente as secas e as inundações; XIX - instituir sistema nacional de gerenciamento de recursos hídricos e definir critérios de outorga de direitos de seu uso; XX instituir diretrizes para (...) saneamento básico. ${ }^{25}$

BRASIL. Constituição
http://www.planalto.gov.br/ccivil 03/constituicao/constituicao.htm Acesso em: 05 de junho de 2015.

22 BRASIL. Constituição Federal do Brasil de 1988. Disponível em: http://www.planalto.gov.br/ccivil_03/constituicao/constituicao.htm Acesso em: 05 de junho de 2015.

23 MACHADO, Paulo Affonso Leme. Direito Ambiental Brasileiro. p. 503.

24 BRASIL. Constituição Federal do Brasil de 1988 . Disponível em: http://www.planalto.gov.br/ccivil_03/constituicao/constituicao.htm Acesso em: 05 de junho de 2015.

25 BRASIL. Constituição Federal do Brasil de 1988. Disponível em: http://www.planalto.gov.br/ccivil_03/constituicao/constituicao.htm Acesso em: 05 de junho de 2015. 
TEIXEIRA, Alessandra Vanessa e GIRELLI, Camile Serraggio, Miriam Fecchio. Direito ambiental comparado: argentina, brasil e o estudo normativo-jurídico de suas águas. Revista Eletrônica Direito e Política, Programa de Pós-Graduação Stricto Sensu em Ciência Jurídica da UNIVALI, Itajaí, v.10, n.3, 2o quadrimestre de 2015. Disponível em: www.univali.br/direitoepolitica - ISSN 1980-7791.

Com relação à competência administrativa, a Constituição estabelece:

Art. 23. É competência comum da União, dos Estados, do Distrito Federal e dos Municípios: (...) VI - proteger o meio ambiente e combater a poluição em qualquer de suas formas; (...) XI - registrar, acompanhar e fiscalizar as concessões de direitos de pesquisa e exploração de recursos hídricos e minerais em seus territórios. ${ }^{26}$

Sobre o que dispõe o art. 23 acima referido, Pes comenta que

É evidente que, para exercitar tais atribuições, existe a necessidade de que sejam elaborados normas e regulamentos, portanto, cabe, sem dúvida, uma produção legislativa dos Estados, do Distrito Federal e dos Municípios sobre àguas, desde que voltada para o combate à poluição e para a proteção do meio ambiente. ${ }^{27}$

Ainda, nesse mesmo contexto, Édis Milaré refere

Se a Constituição conferiu-Ihe poder para "proteger o meio ambiente e combater a poluição em qualquer das suas formas" - competência administrativa -, é óbvio que para cumprir tal missão há que poder legislar sobre a matéria. Acrescente-se, ademais, que a Constituição Federal, entre as inúmeras competências conferidas aos Municípios, entregouIhes a de, em seu território, legislar supletivamente à União e aos Estados sobre a proteção do meio ambiente..$^{28}$

Encerrando os comentários referentes ao art. 23 da CF/88, encerra-se também a abordagem constitucional sobre a proteção das águas no Brasil, passando, então, para a compreensão da proteção ambiental referente às águas na Argentina.

26 BRASIL. Constituição Federal do Brasil de 1988. Disponível em: http://www.planalto.gov.br/ccivil_03/constituicao/constituicao.htm Acesso em: 05 de junho de 2015.

27 PES, João Hélio Ferreira. O Mercosul e as águas: a harmonização, via Mercosul, das normas de proteção às águas transfronteiriças do Brasil e Argentina. p. 44.

${ }^{28}$ MILARÉ, Édis. Direito do ambiente: doutrina, prática, jurisprudência, glossário. 2. ed. São Paulo: Editora Revista dos Tribunais, 2001, p.264. 
TEIXEIRA, Alessandra Vanessa e GIRELLI, Camile Serraggio, Miriam Fecchio. Direito ambiental comparado: argentina, brasil e o estudo normativo-jurídico de suas águas. Revista Eletrônica Direito e Política, Programa de Pós-Graduação Stricto Sensu em Ciência Jurídica da UNIVALI, Itajaí, v.10, n.3, 2o quadrimestre de 2015. Disponível em: www.univali.br/direitoepolitica - ISSN 1980-7791.

As águas ou os recursos hídricos não estão expressamente previstos nas disposições constitucionais que abordam a tutela jurídica dos bens ambientais, pois esses estão incluídos implicitamente na expressão "recursos naturais", usada no art. 41 da Constituição da Nação Argentina. ${ }^{29}$

Como mencionado por Pes, as águas não mereceram tratamento constitucional explícito na Constituição Argentina. No entanto, os arts. 26, 75 (incisos 10, 13 e 18) e o art. 125 contêm disposições relacionadas às águas, conforme segue:

Art. 26.- La navegación de los ríos interiores de la Nación es libre para todas las banderas, con sujeción únicamente a los reglamentos que dicte la autoridad nacional. ${ }^{30}$

De acordo com o art. 26 supra, os rios argentinos, para fins de navegação, são considerados internacionais e qualquer navegação de qualquer país pode navegar naquelas águas, uma vez que se sujeitem às normas editadas pela autoridade central da Nação. ${ }^{31}$

Art. 75.- Corresponde al Congreso: (...)10. Reglamentar la libre navegación de los ríos interiores, habilitar los puertos que considere convenientes, y crear o suprimir aduanas. (...)13. Reglar el comercio con las naciones extranjeras, y de las provincias entre sí. (...)18. Proveer lo conducente a la prosperidad del país, al adelanto y bienestar de todas las provincias, y al progreso de la ilustración, dictando planes de instrucción general y universitaria, y promoviendo la industria, la inmigración, la construcción de ferrocarriles y canales navegables, la colonización de tierras de propiedad nacional, la introducción y establecimiento de nuevas industrias, la importación de capitales extranjeros y la exploración de los ríos interiores, por leyes protectoras de

29 PES, João Hélio Ferreira. O Mercosul e as águas: a harmonização, via Mercosul, das normas de proteção às águas transfronteiriças do Brasil e Argentina. p. 48

30 ARgENTINA. Constitución Nacional. Disponível em: http://www.senado.gov.ar/deInteres. Acesso em: 06 de junho de 2015.

31 PES, João Hélio Ferreira. O Mercosul e as águas: a harmonização, via Mercosul, das normas de proteção às águas transfronteiriças do Brasil e Argentina. p. 48. 
TEIXEIRA, Alessandra Vanessa e GIRELLI, Camile Serraggio, Miriam Fecchio. Direito ambiental comparado: argentina, brasil e o estudo normativo-jurídico de suas águas. Revista Eletrônica Direito e Política, Programa de Pós-Graduação Stricto Sensu em Ciência Jurídica da UNIVALI, Itajaí, v.10, n.3, 2o quadrimestre de 2015. Disponível em: www.univali.br/direitoepolitica - ISSN 1980-7791.

estos fines y por concesiones temporales de privilegios $y$ recompensas de estímulo. ${ }^{32}$

Conforme com o artigo 75, inciso 10, compete ao Congresso da Nação legislar sobre a navegação fluvial; o inciso 13 dispõe que também compete ao Congresso legislar sobre o comércio com as nações estrangeiras e entre as províncias. ${ }^{33}$

Com relação a esse inciso 13, Jorge Atílio Franza: "En el caso del uso del agua para la navegación, todo lo que hace al comercio internacional e interprovincial estaria regulado por el art. 75 inc. 13 de la Constitución". ${ }^{34}$

Ainda, no artigo 75, o inciso 18 refere que compete ao Congresso prover e promover a prosperidade por intermédio de diversas formas, inclusive em relação à exploração dos rios. ${ }^{35}$

Art. 125.- Las provincias pueden celebrar tratados parciales para fines de administración de justicia, de intereses económicos y trabajos de utilidad común, con conocimiento del Congreso Federal; y promover su industria, la inmigración, la construcción de ferrocarriles y canales navegables, la colonización de tierras de propiedad provincial, la introducción y establecimiento de nuevas industrias, la importación de capitales extranjeros y la exploración de sus ríos, por leyes protectoras de estos fines, y con sus recursos propios. Las provincias y la ciudad de Buenos Aires pueden conservar organismos de seguridad social para los empleados públicos y los profesionales; y promover el progreso económico, el desarrollo humano, la generación de empleo, la educación, la ciencia, el conocimiento y la cultura. ${ }^{36}$

32 ARgEnTINA. Constitución Nacional. Disponível em: http://www.senado.gov.ar/deInteres. Acesso em: 06 de junho de 2015.

33 PES, João Hélio Ferreira. O Mercosul e as águas: a harmonização, via Mercosul, das normas de proteção às águas transfronteiriças do Brasil e Argentina. p. 49.

34 FRANZA apud PES, 2005, p. 49.

35 PES, João Hélio Ferreira. O Mercosul e as águas: a harmonização, via Mercosul, das normas de proteção às águas transfronteiriças do Brasil e Argentina. p. 49.

36 ARgENTINA. Constitución Nacional. Disponível em: http://www.senado.gov.ar/deInteres. Acesso em: 06 de junho de 2015. 
TEIXEIRA, Alessandra Vanessa e GIRELLI, Camile Serraggio, Miriam Fecchio. Direito ambiental comparado: argentina, brasil e o estudo normativo-jurídico de suas águas. Revista Eletrônica Direito e Política, Programa de Pós-Graduação Stricto Sensu em Ciência Jurídica da UNIVALI, Itajaí, v.10, n.3, 2o quadrimestre de 2015. Disponível em: www.univali.br/direitoepolitica - ISSN 1980-7791.

Por fim, o art. 125 da Constituição Nacional da Argentina, dispõe sobre os poderes concorrentes, referindo que as províncias têm competência para realizar tratados parciais, desde que com o conhecimento do Congresso Federal e, também, fomentar a exploração de seus rios, mediante leis protetoras. ${ }^{37}$

Percebe-se, então, que na Argentina, as águas não mereceram tratamento constitucional explícito; já no Brasil, a Constituição traz claramente previsões sobre as águas, desde a sua dominialidade, passando pelas competências legislativa, executiva e administrativa, chegando então às disposições referentes a sua fiscalização.

\subsection{As águas nas legislações infraconstitucionais}

Com relação à legislação infraconstitucional, tanto do Brasil quanto da Argentina, a análise vai se restringir às normas federais, uma vez que para uma análise mais completa de todas as normas, neste caso, seria necessário um direcionamento mais específico em relação ao tema.

\subsubsection{No Brasil}

O Brasil tem uma proteção jurídica das águas bastante avançada, se comparada com os demais países vizinhos. Por ser um país que tem uma das maiores reservas de água do planeta, já possuía uma legislação que tratava do assunto antes mesmo da degradação de parte de suas águas: o Código de Águas de $1934 .^{38}$

O Código de Águas, instituído pelo Decreto n. 24.643, de 10.07.1934, dispõe sobre a classificação e utilização das águas, dando ênfase ao aproveitamento do potencial hidrelétrico que, na década de 30, representava uma condicionante do

\footnotetext{
37 PES, João Hélio Ferreira. O Mercosul e as águas: a harmonização, via Mercosul, das normas de proteção às águas transfronteiriças do Brasil e Argentina, p. 49.

38 PES, João Hélio Ferreira. O Mercosul e as águas: a harmonização, via Mercosul, das normas de proteção às águas transfronteiriças do Brasil e Argentina. p. 53.
} 
TEIXEIRA, Alessandra Vanessa e GIRELLI, Camile Serraggio, Miriam Fecchio. Direito ambiental comparado: argentina, brasil e o estudo normativo-jurídico de suas águas. Revista Eletrônica Direito e Política, Programa de Pós-Graduação Stricto Sensu em Ciência Jurídica da UNIVALI, Itajaí, v.10, n.3, 2o quadrimestre de 2015. Disponível em: www.univali.br/direitoepolitica - ISSN 1980-7791.

progresso industrial que o Brasil buscava. Foi o primeiro diploma legal que possibilitou ao Poder Público disciplinar o aproveitamento industrial das águas e foi editado na forma de Decreto, e não de lei, por ser ato do então Governo Provisório, decorrente da Revolução de $1930 .^{39}$

Observa-se que o Código de Águas ${ }^{40}$ significa um marco na legislação brasileira. No entanto, ele foi ajustado aos interesses e necessidades da década de 30 e, com o passar do tempo a norma deixou de se adequar à realidade. Dessa forma, vários dispositivos do Código de Águas foram derrogados, especialmente pela Lei da Política Nacional de Recursos Hídricos. ${ }^{41}$

Além do Código de Águas, o Brasil tem uma lei, que pode ser considerada como o grande documento regulamentador da matéria, que é a Lei da Política Nacional de Recursos Hídricos. Pes afirma que "diversos dispositivos do Código de Águas foram derrogados pelas legislações posteriores, entre elas a Lei da Política Nacional de Recursos Hídricos". 42

A Lei n. 9.433, de 08.01.1997 regulamentou a Política Nacional de Recursos Hídricos e criou o Sistema Nacional de Gerenciamento de Recursos Hídricos, regulamentando o inciso XIX, do art. 21 da Constituição Federal de 1988, que confere à União a instituição do Sistema Nacional de Recursos Hídricos e a definição de critérios para outorga de direitos de seu uso. ${ }^{43}$

39 PES, João Hélio Ferreira. O Mercosul e as águas: a harmonização, via Mercosul, das normas de proteção às águas transfronteiriças do Brasil e Argentina, p. 53.

${ }^{40}$ BRASIL. Decreto n. 24.643, de 10 de julho de 1934. Decreta o Código de Águas. Disponível em: http://www.planalto.gov.br/ccivil_03/decreto/d24643.htm. Acesso em: 06 de junho de 2015

41 PES, João Hélio Ferreira. O Mercosul e as águas: a harmonização, via Mercosul, das normas de proteção às águas transfronteiriças do Brasil e Argentina. p. 55.

42 PES, João Hélio Ferreira. O Mercosul e as águas: a harmonização, via Mercosul, das normas de proteção às águas transfronteiriças do Brasil e Argentina. p. 55.

43 BRASIL. Lei n. 9.433, de 08 de janeiro de 1997. Institui a Política Nacional de Recursos Hídricos, cria o Sistema Nacional de Gerenciamento de Recursos Hídricos, regulamenta o inciso XIX do art. 21 da Constituição Federal, e altera o art. $1^{\circ}$ da Lei no 8.001, de 13 de março de 1990, que modificou a Lei no 7.990, de 28 de dezembro de 1989. Disponível em: http://www.planalto.gov.br/ccivil_03/Leis/L9433.htm. Acesso em: 06 de junho de 2015 
TEIXEIRA, Alessandra Vanessa e GIRELLI, Camile Serraggio, Miriam Fecchio. Direito ambiental comparado: argentina, brasil e o estudo normativo-jurídico de suas águas. Revista Eletrônica Direito e Política, Programa de Pós-Graduação Stricto Sensu em Ciência Jurídica da UNIVALI, Itajaí, v.10, n.3, 2o quadrimestre de 2015. Disponível em: www.univali.br/direitoepolitica - ISSN 1980-7791.

Por se tratar de uma lei bastante completa em relação à proteção jurídica das águas, é importante ater-se um pouco a ela. $O$ artigo $1^{\circ}$ traz os princípios da Política Nacional de Recursos Hídricos:

Art. $1^{0}$ A Política Nacional de Recursos Hídricos baseia-se nos seguintes fundamentos: I - a água é um bem de domínio público; II - a água é um recurso natural limitado, dotado de valor econômico; III - em situações de escassez, o uso prioritário dos recursos hídricos é o consumo humano e a dessedentação de animais; IV - a gestão dos recursos hídricos deve sempre proporcionar o uso múltiplo das águas; V - a bacia hidrográfica é a unidade territorial para implementação da Política Nacional de Recursos Hídricos e atuação do Sistema Nacional de Gerenciamento de Recursos Hídricos; VI - a gestão dos recursos hídricos deve ser descentralizada e contar com a participação do Poder Público, dos usuários e das comunidades. ${ }^{44}$

Comentando sobre o artigo acima, Celso Fiorillo diz que o inciso I não é válido, pois reflete uma inconstitucionalidade. No inciso I declarou-se que a água é um bem de domínio público, no entanto, "a água é um bem tipicamente ambiental, sendo, portanto, de uso comum do povo". Por isso, o autor afirma que "o art. 1 , I, encontra-se em total desarmonia com o Texto Constitucional, não encontrando neste qualquer suporte de validade". ${ }^{45}$

Ainda com relação ao art. $1^{\circ}$, Paulo de Bessa Antunes se posiciona, afirmando que "o principal aspecto que pode ser compreendido desses princípios é que a nova concepção legal busca encerrar com a verdadeira apropriação privada e graciosa dos recursos hídricos". O autor refere como exemplos de grandes usuários de recursos hídricos, a indústria e a agricultura, os quais ganham vantagens e dividendos com a utilização desses recursos naturais e não pagam nada pela atividade. Refere também que, "a recuperação e manutenção das boas

44 BRASIL. Lei n. 9.433, de 08 de janeiro de 1997. Disponível em: http://www.planalto.gov.br/ccivil_03/Leis/L9433.htm. Acesso em: 06 de junho de 2015.

${ }^{45}$ FIORILLO, Celso Antonio Pacheco. Curso de direito ambiental brasileiro. 12. ed. São Paulo: Saraiva, 2011, p. 296. 
TEIXEIRA, Alessandra Vanessa e GIRELLI, Camile Serraggio, Miriam Fecchio. Direito ambiental comparado: argentina, brasil e o estudo normativo-jurídico de suas águas. Revista Eletrônica Direito e Política, Programa de Pós-Graduação Stricto Sensu em Ciência Jurídica da UNIVALI, Itajaí, v.10, n.3, 2o quadrimestre de 2015. Disponível em: www.univali.br/direitoepolitica - ISSN 1980-7791.

condições sanitárias e ambientais dos recursos hídricos é um encargo de toda a sociedade que, com seus impostos, subsidia de forma inaceitável diversas atividades privadas". ${ }^{46}$

São encontrados na Lei da Política Nacional de Recursos Hídricos, também, dispositivos que trazem os seus objetivos (art. $2^{\circ}$ ), as diretrizes gerais de ação, devendo ser destacadas as que preveem a "gestão sistemática dos recursos hídricos, sem dissociação dos aspectos de quantidade e qualidade" e "a integração da gestão de recursos hídricos com a gestão ambiental" (art. $3^{\circ}$ ) e os instrumentos capazes de torna-la exequível (art. $\left.5^{\circ}\right) \cdot{ }^{47}$

Os planos de recursos hídricos estão estabelecidos nos artigos $6^{\circ}, 7^{\circ}$ e $8^{\circ}$ da Lei $9.433 / 97$, os quais além de conceituar o que são esses planos, também elencam o conteúdo mínimo dos mesmos. Os art. $9^{\circ}$ e 10 preveem o enquadramento dos corpos de água em classes, segundo os usos preponderantes da água. Dos artigos 11 a 18 estão as disposições referentes à outorga de direitos de uso de recursos hídricos, preceituando os objetivos do regime de outorga, quais os usos de recursos hídricos estão sujeitos a ela, a competência para a sua efetivação, possibilidades de suspensão da outorga e prazo. Com relação à cobrança do uso de recursos hídricos, são os artigos 19, 20, 21 e 22 que a regulamentam, trazendo algumas observações para fixação da cobrança e informando sobre a aplicação dos valores arrecadados com ela.

O Título II da Lei 9.433/97 dispõe, a partir do art. 32, sobre o Sistema Nacional de Gerenciamento de Recursos Hídricos, trazendo seus objetivos e no art. 33 a sua composição:

Art. 33. Integram o Sistema Nacional de Gerenciamento de Recursos Hídricos: I - o Conselho Nacional de Recursos Hídricos; I-A. - a Agência Nacional de Águas; II - os Conselhos de Recursos Hídricos dos Estados e do Distrito

\footnotetext{
${ }^{46}$ ANTUNES, Paulo de Bessa. Direito Ambiental. 14 ed., São Paulo: Atlas, 2012. p. 913.

47 PES, João Hélio Ferreira. O Mercosul e as águas: a harmonização, via Mercosul, das normas de proteção às águas transfronteiriças do Brasil e Argentina. p. 57.
} 
TEIXEIRA, Alessandra Vanessa e GIRELLI, Camile Serraggio, Miriam Fecchio. Direito ambiental comparado: argentina, brasil e o estudo normativo-jurídico de suas águas. Revista Eletrônica Direito e Política, Programa de Pós-Graduação Stricto Sensu em Ciência Jurídica da UNIVALI, Itajaí, v.10, n.3, 2o quadrimestre de 2015. Disponível em: www.univali.br/direitoepolitica - ISSN 1980-7791.

Federal; III - os Comitês de Bacia Hidrográfica; IV - os órgãos dos poderes públicos federal, estaduais, do Distrito Federal e municipais cujas competências se relacionem com a gestão de recursos hídricos; V - as Agências de Água. ${ }^{48}$

Pes explica que "esse sistema é nacional e não federal. Por isso, é integrado por órgãos dos três níveis de poder, pelos Conselhos Estaduais e pelos Comitês de Bacia quer federais, quer estaduais". ${ }^{49}$

Dos artigos 34 ao 46 da Lei 9.433/97, encontram-se disposições sobre cada um dos integrantes do Sistema Nacional de Gerenciamento de Recursos Hídricos, com relação à composição desses órgãos, competência e área de atuação e requisitos para sua criação. Já o art. 49 tipifica as infrações às normas de utilização dos recursos hídricos e o art. 50 traz as penalidades por infração de qualquer disposição legal ou regulamentar relacionadas à utilização de recursos hídricos.

Por fim, a Lei da Política Nacional de Recursos Hídricos, Lei n. 9.433/97, demonstra a relevância das águas para a vida, onde há uma consagração da concepção do Direito Público em substituição ao Direito Privado, uma vez que estes favoreciam os interesses individuais, ao invés do bem coletivo.

Diversas são as normas brasileiras de proteção às águas, pois além das que já foram analisadas, "há leis, decretos, resoluções e regulamentos, alguns anteriores ao Código de Águas de 1934, mas a maioria é recente" ${ }^{\prime 50}$. No entanto, serão mencionadas as que são consideradas mais importantes para este estudo. No Código Civil de 2002, destaca-se a disposição acrescentada pelo art. 1.291: "O possuidor do imóvel superior não poderá poluir as águas indispensáveis às

\footnotetext{
48 BRASIL. Lei n. 9.433, de 08 de janeiro de 1997. Disponível em: http://www.planalto.gov.br/ccivil_03/Leis/L9433.htm. Acesso em: 06 de junho de 2015.

49 PES, João Hélio Ferreira. O Mercosul e as águas: a harmonização, via Mercosul, das normas de proteção às águas transfronteiriças do Brasil e Argentina. p. 59.

50 PES, João Hélio Ferreira. O Mercosul e as águas: a harmonização, via Mercosul, das normas de proteção às águas transfronteiriças do Brasil e Argentina. p. 60.
} 
TEIXEIRA, Alessandra Vanessa e GIRELLI, Camile Serraggio, Miriam Fecchio. Direito ambiental comparado: argentina, brasil e o estudo normativo-jurídico de suas águas. Revista Eletrônica Direito e Política, Programa de Pós-Graduação Stricto Sensu em Ciência Jurídica da UNIVALI, Itajaí, v.10, n.3, 2o quadrimestre de 2015. Disponível em: www.univali.br/direitoepolitica - ISSN 1980-7791.

primeiras necessidades da vida dos possuidores dos imóveis inferiores; as demais, que poluir, deverá recuperar, ressarcindo os danos que estes sofrerem, se não for possível a recuperação ou o desvio do curso artificial das águas" ${ }^{\prime 1}$.

O Código Penal, em seu art. 270, dispõe: "Envenenar água potável, de uso comum ou particular (...) Pena - reclusão, de dez a quinze anos". Ainda, o art. 271 preceitua: "Corromper ou poluir água potável, de uso comum ou particular, tornando-a imprópria para consumo ou nociva à saúde: Pena - reclusão, de dois a cinco anos" ${ }^{\prime \prime 2}$.

A Lei n 6.938 de 31.08.1981, que dispõe sobre a Política Nacional do Meio Ambiente, referiu-se às águas em seu art. $8^{\circ}$ : "Compete ao CONAMA: (...) VII estabelecer normas, critérios e padrões relativos ao controle e à manutenção da qualidade do meio ambiente com vistas ao uso racional dos recursos ambientais, principalmente os hídricos" ${ }^{53}$.

O CONAMA (Conselho Nacional do Meio Ambiente), por sua vez e no exercício de sua competência, editou a Resolução $n^{\circ} 20^{54}$, de 18.06.1986, "que reformulou a classificação das águas, padrões de qualidade e padrões de emissão de efluentes" e, também, "estabelece uma classificação para todo o tipo de águas existentes no território brasileiro" ${ }^{55}$.

Ainda, tem a Lei 9.966, de 28.04.2000 que dispõe sobre a prevenção, o controle

${ }^{51}$ BRASIL. Lei $\mathbf{n}^{\circ} \mathbf{1 0 . 4 0 6}$, de 10 de janeiro de 2002. Institui o Código Civil. Disponível em: http://www.planalto.gov.br/ccivil_03/Leis/2002/L10406.htm. Acesso em: 07 de junho de 2015.

52 BRASIL. Decreto-lei $\mathbf{n}^{\circ}$ 2.848, de 7 de dezembro de 1940. Código Penal. Disponível em: http://www.planalto.gov.br/ccivil_03/Decreto-Lei/Del2848.htm. Acesso em: 07 de junho de 2015.

53 BRASIL. Lei 6.938 de 31 de agosto de 1981. Dispõe sobre a Política Nacional do Meio Ambiente, seus fins e mecanismos de formulação e aplicação, e dá outras providências. Disponível em: http://www.planalto.gov.br/ccivil_03/leis/L6938.htm. Acesso em: 07 de junho de 2015.

54 BRASIL. Resolução CONAMA $n^{\circ}$ 20, de 18 de junho de 1986. Disponível em: http://www.mma.gov.br/port/conama/res/res86/res2086.html. Acesso em: 07 de junho de 2015.

55 PES, João Hélio Ferreira. O Mercosul e as águas: a harmonização, via Mercosul, das normas de proteção às águas transfronteiriças do Brasil e Argentina. p. 62. 
TEIXEIRA, Alessandra Vanessa e GIRELLI, Camile Serraggio, Miriam Fecchio. Direito ambiental comparado: argentina, brasil e o estudo normativo-jurídico de suas águas. Revista Eletrônica Direito e Política, Programa de Pós-Graduação Stricto Sensu em Ciência Jurídica da UNIVALI, Itajaí, v.10, n.3, 2o quadrimestre de 2015. Disponível em: www.univali.br/direitoepolitica - ISSN 1980-7791.

e a fiscalização da poluição causada por lançamento de óleo e outras substâncias nocivas ou perigosas em águas sob jurisdição nacional. ${ }^{56} \mathrm{E}$, também, a Lei 9.984, de 17.07.2000, que criou a Agência Nacional das Águas (ANA) como entidade federal de implementação da Política Nacional de Recursos Hídricos, a qual tem atribuição de órgão técnico e executivo. ${ }^{57}$

Com o disposto referente às normas infraconstitucionais brasileiras de proteção às águas, mesmo não tendo abordado todas, percebe-se a postura protecionista que o país assume perante seus recursos hídricos. Agora, passa-se à análise das águas à luz da legislação nacional argentina.

\subsubsection{Na Argentina}

Na Argentina, não existe uma lei infraconstitucional nacional, que trate de forma abrangente a proteção das águas/recursos hídricos e nem mesmo lei que disponha sobre uma política nacional para estes recursos.

A legislação nacional assim como as legislações provinciais proíbem lançar aos rios resíduos cloacais e industriais sem tratamento prévio. Tanto a legislação nacional como as provinciais organizam o abastecimento de água potável e estabelecem limites para o controle da contaminação. As normas de proteção às águas em várias províncias são mais abrangentes que as editadas pela nação. ${ }^{58}$

56 BRASIL. Lei n 9.966, de 28 de abril de 2000. Dispõe sobre a prevenção, o controle e a fiscalização da poluição causada por lançamento de óleo e outras substâncias nocivas ou perigosas em águas sob jurisdição nacional e dá outras providências. Disponível em: http://www.planalto.gov.br/ccivil_03/leis/L9966.htm. Acesso em: 07 de junho de 2015.

57 BRASIL. Lei n 9.984, de 17 de julho de 2000. Dispõe sobre a criação da Agência Nacional de Águas - ANA, entidade federal de implementação da Política Nacional de Recursos Hídricos e de coordenação do Sistema Nacional de Gerenciamento de Recursos Hídricos, e dá outras providências. Disponível em: http://www.planalto.gov.br/ccivil_03/leis/l9984.htm. Acesso em: 07 de junho de 2015.

58 PES, João Hélio Ferreira. O Mercosul e as águas: a harmonização, via Mercosul, das normas de proteção às águas transfronteiriças do Brasil e Argentina. p. 64. 
TEIXEIRA, Alessandra Vanessa e GIRELLI, Camile Serraggio, Miriam Fecchio. Direito ambiental comparado: argentina, brasil e o estudo normativo-jurídico de suas águas. Revista Eletrônica Direito e Política, Programa de Pós-Graduação Stricto Sensu em Ciência Jurídica da UNIVALI, Itajaí, v.10, n.3, 2o quadrimestre de 2015. Disponível em: www.univali.br/direitoepolitica - ISSN 1980-7791.

Tendo em vista a comparação jurídica sobre as águas entre as legislações do Brasil e Argentina, a análise da legislação argentina restringe-se às normas jurídicas nacionais, assim como quando do estudo da legislação infraconstitucional do Brasil. E, como não existem leis específicas sobre as águas, busca-se demonstrar outras normas e resoluções que abordem a temática das águas.

Existem leis sobre os acordos e tratados internacionais, aprovadas pelo Congresso da Nação Argentina, que trazem menções às águas, entretanto não se tratam de leis específicas da Argentina, pois abrangem outros países como Bolívia, Brasil, Paraguai e Uruguai, logo, estas leis não serão aqui referidas.

O Decreto Nacional n 674, de 24 de maio de 1989, trata-se do "principal instrumento normativo de proteção à contaminação das águas na Argentina". Tal decreto "foi editado com diversas justificativas, entre elas a de que em dos objetivos dessa norma é controlar a contaminação hídrica e preservar os cursos d'água"59.

Referido Decreto possui alguns considerandos, entre os quais destaca-se:

Que es objetivo de esta normativa impulsar a todo establecimiento a construir sus unidades de tratamento de vertidos en el menor tempo posible, para así controlar la contaminación hídrica y preservar los cursos de agua de su deterioro. ${ }^{60}$

Para Pes, o Decreto Nacional 674/89

[...] tem a finalidade de manter um adequado nível de qualidade das águas superficiais e subterrâneas, de impedir a acumulação de compostos tóxicos ou perigosos capazes de contaminar as águas, evitar qualquer ação que possa ser

59 PES, João Hélio Ferreira. O Mercosul e as águas: a harmonização, via Mercosul, das normas de proteção às águas transfronteiriças do Brasil e Argentina. p. 66.

60 ARGENTINA. Decreto Nacional 674/89. Decreto reglamentario de la Ley 13.577 de Obras Sanitarias de la Nación. Disponível em: http://www2.medioambiente.gov.ar/mlegal/agua/dec674_89.htm. Acesso em: 08 de junho de 2015. 
TEIXEIRA, Alessandra Vanessa e GIRELLI, Camile Serraggio, Miriam Fecchio. Direito ambiental comparado: argentina, brasil e o estudo normativo-jurídico de suas águas. Revista Eletrônica Direito e Política, Programa de Pós-Graduação Stricto Sensu em Ciência Jurídica da UNIVALI, Itajaí, v.10, n.3, 2o quadrimestre de 2015. Disponível em: www.univali.br/direitoepolitica - ISSN 1980-7791.

causa direta ou indireta de degradação e favorecer o uso correto e adequado dos recursos hídricos. ${ }^{61}$

Referido Decreto foi editado antes da privatização da empresa Obras Sanitárias de la Nación, em virtude disso vários artigos fazem referência a essa empresa. Tendo em vista o processo de privatização, foi editado pelo Poder Executivo o Decreto Nacional n. 776, de 12.05.1992 ${ }^{62}$, o qual transfere todas as faculdades e obrigações da empresa ora mencionada para a Dirección de Contaminación Hídrica, esta vinculada à Secretaria de Recursos Naturales y Ambiente Humano. ${ }^{63}$ Além desses Decretos já mencionados, existe mais um que é relacionado às privatizações de águas, que é o Decreto Nacional n. 999, de 18.06.1992. ${ }^{64}$

Merecem ser citadas algumas leis, decretos e resoluções que não são específicos das águas, mas que tratam do tema, quais sejam: Lei Nacional n. 25.675, de 06.11.2002 ${ }^{65}$; Lei Nacional n. 25.831, de 26.11.200366; Lei Nacional n. 23.879, de 28.09.1990. ${ }^{67}$

61 PES, João Hélio Ferreira. O Mercosul e as águas: a harmonização, via Mercosul, das normas de proteção às águas transfronteiriças do Brasil e Argentina. p. 66.

62 ARgEnTINA. Decreto Nacional 776/92. Creación de la Dirección de Contaminación Hidríca. Disponível em: http://www2.medioambiente.gov.ar/mlegal/marco/dec776_92.htm. Acesso em: 08 de junho de 2015.

63 PES, João Hélio Ferreira. O Mercosul e as águas: a harmonização, via Mercosul, das normas de proteção às águas transfronteiriças do Brasil e Argentina. p. 67.

64 ARGENTINA. Decreto 999/92. Apruébase el reglamento administrativo regulatorio de los distintos aspectos de los servicios públicos de provisión de agua potable y desagües cloacales de competencia de Obras Sanitarias de la Nación. Disponível em: http://mepriv.mecon.gov.ar/Normas/999-92.htm. Acesso em: 08 de junho de 2015.

65 ARgentinA. Ley Nacional 25.675. Ley General del Ambiente. Disponível em: http://www2.medioambiente.gov.ar/mlegal/marco/ley25675.htm. Acesso em: 08 de junho de 2015

${ }^{66}$ ARGENTINA. Ley Nacional 25.831. Régimen de libre acceso a la información pública ambiental. Disponível em: http://www2.medioambiente.gov.ar/mlegal/marco/ley25831.htm. Acesso em: 08 de junho de 2015.

67 ARGENTINA. Ley Nacional 23.879. Impacto ambiental de obras hidráulicas con aprovechamiento energético. Disponível em: http://www2.medioambiente.gov.ar/mlegal/eia/ley23879.htm. Acesso em: 08 de junho de 2015. 
TEIXEIRA, Alessandra Vanessa e GIRELLI, Camile Serraggio, Miriam Fecchio. Direito ambiental comparado: argentina, brasil e o estudo normativo-jurídico de suas águas. Revista Eletrônica Direito e Política, Programa de Pós-Graduação Stricto Sensu em Ciência Jurídica da UNIVALI, Itajaí, v.10, n.3, 2o quadrimestre de 2015. Disponível em: www.univali.br/direitoepolitica - ISSN 1980-7791.

\section{CONSIDERAÇÕES FINAIS}

Para a evolução da ciência do direito ambiental, a importância do método comparado é inegável, uma vez que ele não tenta exaurir em seus estudos a questão levantada neste artigo.

O que se pretendeu foi estudar o método comparado e aplica-lo no direito ambiental em um caso concreto, demonstrando as previsões de proteção jurídica das águas nas Constituições e algumas normas jurídicas de cada país, tornandose um norte para as futuras percepções sobre a problemática da aplicação da legislação ambiental nos países.

A comparação possui uma finalidade muito clara, que é extrair dados que demonstrem as vantagens e desvantagens dos objetos comparados, permitindo a formulação de contribuições ao desenvolvimento da ciência e dos sistemas jurídicos analisados. Ainda, a comparação não serve para apenas saciar a mera curiosidade do pesquisador, mas sim para efetivamente gerar avanços científicos e aprimoramentos normativos.

Sendo assim, a partir do estudo comparativo das legislações constitucionais e infraconstitucionais do Brasil e da Argentina referente à proteção das águas, conclui-se que as águas do Brasil estão melhor amparadas, pois há previsões explícitas na Constituição vigente e ainda, conta com um Código de Águas e Leis específicas que tratam do assunto de forma bastante completa. No que tange às águas da Argentina, falta uma lei que institua de forma ampla o direito das águas naquela nação, como um Código de Águas Nacional. O que acontece na Argentina é que este tipo de lei é editado apenas pelas províncias (e não são todas), ou seja, cada uma das províncias tem seu próprio Código de Águas.

Acredita-se que, através do estudo comparado do Direito Ambiental, possa se encontrar soluções para os problemas ambientais que tanto assolam o planeta, buscando um meio ambiente saudável para todos. 
TEIXEIRA, Alessandra Vanessa e GIRELLI, Camile Serraggio, Miriam Fecchio. Direito ambiental comparado: argentina, brasil e o estudo normativo-jurídico de suas águas. Revista Eletrônica Direito e Política, Programa de Pós-Graduação Stricto Sensu em Ciência Jurídica da UNIVALI, Itajaí, v.10, n.3, 2o quadrimestre de 2015. Disponível em: www.univali.br/direitoepolitica - ISSN 1980-7791.

\section{REFERÊNCIAS DAS FONTES CITADAS}

ANCEL, Marc. Utilidade e Métodos do Direito Comparado. Tradução de Sérgio José Porto. Porto Alegre, Fabris, 1980.

ANTUNES, Paulo de Bessa. Direito Ambiental. 11 ed., Rio de Janeiro: Lumen Juris, 2008.

Direito Ambiental. 14 ed., São Paulo: Atlas, 2012.

ARGENTINA. Constitución Nacional. Disponível em:

http://www.senado.gov.ar/deInteres. Acesso em: 06 de junho de 2015.

Decreto Nacional 674/89. Decreto reglamentario de la Ley 13.577 de Obras Sanitarias de la Nación. Disponível em: http://www2.medioambiente.gov.ar/mlegal/agua/dec674 89.htm. Acesso em: 08 de junho de 2015.

Decreto Nacional 776/92. Creación de la Dirección de Contaminación Hidríca. Disponível em: http://www2.medioambiente.gov.ar/mlegal/marco/dec776 92.htm. Acesso em: 08 de junho de 2015.

Decreto 999/92. Apruébase el reglamento administrativo regulatorio de los distintos aspectos de los servicios públicos de provisión de agua potable y desagües cloacales de competencia de Obras Sanitarias de la Nación. Disponível em: http://mepriv.mecon.gov.ar/Normas/999-92.htm. Acesso em: 08 de junho de 2015.

Ley Nacional 25.675. Ley General del Ambiente. Disponível em: http://www2.medioambiente.gov.ar/mlegal/marco/ley25675.htm. Acesso em: 08 de junho de 2015.

Ley Nacional 25.831. Régimen de libre acceso a la información pública ambiental.

Disponível em: http://www2.medioambiente.gov.ar/mlegal/marco/ley25831.htm. Acesso em: 08 de junho de 2015.

Ley Nacional 23.879. Impacto ambiental de obras hidráulicas con aprovechamiento energético.

Disponível em: http://www2.medioambiente.gov.ar/mlegal/eia/ley23879.htm. Acesso em: 08 de junho de 2015. 
TEIXEIRA, Alessandra Vanessa e GIRELLI, Camile Serraggio, Miriam Fecchio. Direito ambiental comparado: argentina, brasil e o estudo normativo-jurídico de suas águas. Revista Eletrônica Direito e Política, Programa de Pós-Graduação Stricto Sensu em Ciência Jurídica da UNIVALI, Itajaí, v.10, n.3, 2o quadrimestre de 2015. Disponível em: www.univali.br/direitoepolitica - ISSN 1980-7791.

BELL, John. Legal Research and the Distinctiveness od Comparative Law. In: HOECKE, Mark Van (ed.). Methodologies of Legal Research: Which Kind of Method for What Kind of Discipline? Oxford: Hart Publishing, 2011.

BRASIL. Constituição Federal do Brasil de 1988. Disponível em: http://www.planalto.gov.br/ccivil_03/constituicao/constituicao.htm Acesso em: 05 de junho de 2015.

. Decreto n. 24.643, de 10 de julho de 1934. Decreta o Código de Águas. Disponível em: http://www.planalto.gov.br/ccivil 03/decreto/d24643.htm. Acesso em: 06 de junho de 2015.

Decreto-lei n².848, de 7 de dezembro de 1940. Código Penal. Disponível em: http://www.planalto.gov.br/ccivil 03/Decreto-Lei/Del2848.htm. Acesso em: 07 de junho de 2015.

Lei 6.938 de 31 de agosto de 1981. Dispõe sobre a Política Nacional do Meio Ambiente, seus fins e mecanismos de formulação e aplicação, e dá outras providências. Disponível em: http://www.planalto.gov.br/ccivil 03/leis/L6938.htm. Acesso em: 07 de junho de 2015.

. Lei n. 9.433, de 08 de janeiro de 1997. Institui a Política Nacional de Recursos Hídricos, cria o Sistema Nacional de Gerenciamento de Recursos Hídricos, regulamenta o inciso XIX do art. 21 da Constituição Federal, e altera o art. $1^{\circ}$ da Lei no 8.001, de 13 de março de 1990, que modificou a Lei no 7.990, de 28 de dezembro de 1989. Disponível em: http://www.planalto.gov.br/ccivil 03/Leis/L9433.htm. Acesso em: 06 de junho de 2015.

Lei $n^{\circ}$ 9.966, de 28 de abril de 2000. Dispõe sobre a prevenção, o controle e a fiscalização da poluição causada por lançamento de óleo e outras substâncias nocivas ou perigosas em águas sob jurisdição nacional e dá outras providências.

Disponível

em:

http://www.planalto.gov.br/ccivil 03/leis/L9966.htm. Acesso em: 07 de junho de 2015. 
TEIXEIRA, Alessandra Vanessa e GIRELLI, Camile Serraggio, Miriam Fecchio. Direito ambiental comparado: argentina, brasil e o estudo normativo-jurídico de suas águas. Revista Eletrônica Direito e Política, Programa de Pós-Graduação Stricto Sensu em Ciência Jurídica da UNIVALI, Itajaí, v.10, n.3, 2o quadrimestre de 2015. Disponível em: www.univali.br/direitoepolitica - ISSN 1980-7791.

. Lei n 9.984, de 17 de julho de 2000. Dispõe sobre a criação da Agência Nacional de Águas - ANA, entidade federal de implementação da Política Nacional de Recursos Hídricos e de coordenação do Sistema Nacional de Gerenciamento de Recursos Hídricos, e dá outras providências. Disponível em: http://www.planalto.gov.br/ccivil 03/leis/19984.htm. Acesso em: 07 de junho de 2015.

Lei $\mathrm{n}^{\circ}$ 10.406, de 10 de janeiro de 2002. Institui o Código Civil. Disponível em: http://www.planalto.gov.br/ccivil 03/Leis/2002/L10406.htm. Acesso em: 07 de junho de 2015.

Resolução CONAMA n 20, de 18 de junho de 1986. Disponível em: http://www.mma.gov.br/port/conama/res/res86/res2086.html. Acesso em: 07 de junho de 2015.

FIORILLO, Celso Antonio Pacheco. Curso de direito ambiental brasileiro. 12. ed. São Paulo: Saraiva, 2011.

GINSBURG, TOM. MONATERI, Pier Giuseppe. PARISI, Francesco. Classics in Comparative Law: An Introduction. Disponível em: https://snt146. mail.live.com/mail/ViewOfficePreview.aspx?messageid=mgKp1w4 hcE5RGmnAAhWtezyg2\&folderid=flinbox\&attindex $=0 \& c p=-$

$1 \&$ attdepth $=0 \& n=18404086$. Acesso em : 27 de maio de 2015 .

MACHADO, Paulo Affonso Leme. Direito Ambiental Brasileiro. 22. ed. São Paulo: Malheiros Editores, 2014.

MACHADO, Roberto Ferreira. Água um direito fundamental. In: Revista Direito Ambiental e sociedade, Caxias do Sul, v. 1, n. 1, p. 348, jan./jun. 2011.

MARRARA, Tiago. Método Comparativo e Direito Administrativo. In: http://www.unigran.br/revista_juridica/ed_atual/artigos/artigo02.pdf.

MEZZAROBA, Orides. MONTEIRO, Cláudia Servilha. Manual de Metodologia da Pesquisa no Direito. São Paulo: Saraiva, 2003.

MILARÉ, Édis. Direito do ambiente: doutrina, prática, jurisprudência, glossário. 2. ed. São Paulo: Editora Revista dos Tribunais, 2001. 
TEIXEIRA, Alessandra Vanessa e GIRELLI, Camile Serraggio, Miriam Fecchio. Direito ambiental comparado: argentina, brasil e o estudo normativo-jurídico de suas águas. Revista Eletrônica Direito e Política, Programa de Pós-Graduação Stricto Sensu em Ciência Jurídica da UNIVALI, Itajaí, v.10, n.3, 2o quadrimestre de 2015. Disponível em: www.univali.br/direitoepolitica - ISSN 1980-7791.

MONTESQUIEU, Charles Louis de Secondat. Do Espírito das Leis. Introdução e Notas de Gonzague Truc; Tradução de Fernando Henrique Cardoso e Leôncio Martins Rodrigues. $2^{a}$ ed. Coleção: Os Pensadores. São Paulo: Abril Cultural, 1979.

MUKAI, Toshio. Direito ambiental sistematizado. 4. ed. Rio de Janeiro: Forense Universitária, 2004.

PES, João Hélio Ferreira. 0 Mercosul e as águas: a harmonização, via Mercosul, das normas de proteção às águas transfronteiriças do Brasil e Argentina. Santa Maria: Ed. da UFSM, 2005.

RAMOS, Erasmo Marcos. Direito ambiental comparado: Brasil-Alemanha-EUA: uma análise exemplificada dos instrumentos ambientais brasileiros à luz do direito comparado. Maringá: Midiograf II, 2009.

SACCO, Rodolfo. Introdução ao Direito Comparado. Tradução Véra Jacob de Fradera. São Paulo: Editora Revista dos Tribunais, 2001.

ZWEIGERT, See K. KÖTZ, H. An Introduction to Comparative Law, 3rd edn (traslated by Tony Weir, Oxford, Oxford University Press, 1998) 15-18, 58-62. In: In: HOECKE, Mark Van (ed.). Methodologies of Legal Research: Which Kind of Method for What Kind of Discipline? Oxford: Hart Publishing, 2011.

Submetido em: Maio/2015

Aprovado em: Julho/2015 